\title{
Tekrarlayan Olumsuz Öz-Derin Düşünce Ölçeği Türkçe Formu: Geçerlik ve Güvenirlik Çalışması
}

\begin{abstract}
Hakan SARIÇAM *
Ahmet AKIN **

Öz

Bu araştırmanın amacı Elliot ve Coker (2008) tarafından geliştirilen Tekrarlayan Olumsuz Öz-Derin Düşünce Ölçeğini Türkçeye uyarlamak ve ölçeğin geçerlik ve güvenirlik analizlerini yapmaktır. Araştırmaya iki ayrı üniversiteden (286 $\neg+287$ ) toplam 573 üniversite öğrencisi katılmıştır. Ölçeğin psikometrik özellikleri, test-tekrar test, iç tutarlık, açımlayıcı ve doğrulayıcı faktör analizi ve ölçüt geçerliği yöntemleriyle incelenmiştir. Ölçüt bağıntılı geçerlik için Tekrarlayan Olumsuz Öz-Derin Düşünce Ölçeği ile birlikte ÖzDüşünüm Ölçeği kullanılmıştır. KMO örneklem uygunluk katsayısı .82, Barlett testi $\chi 2$ değeri 665,102 (p< $.001, \mathrm{sd}=36$ ) bulunmuştur. Ölçeğin yapı geçerliği için uygulanan doğrulayıcı faktör analizinde orijinal formla tutarlı olarak 10 maddenin tek boyutlu modelinin uyum indeksi değerleri: $x 2=53,97, \mathrm{sd}=31$, $\mathrm{p}=.006$, $\mathrm{RMSEA}=.051, \mathrm{CFI}=.99, \mathrm{GFI}=.96, \mathrm{IFI}=.99, \mathrm{NFI}=.97, \mathrm{SRMR}=.039$ olarak hesaplanmıştır. Ölçeğin faktör yükleri .44 ile .78 arasında sıralanmakta olup; Cronbach alfa iç tutarlık katsayısı .86 olarak bulunmuştur. Ölçüt geçerliği çalışmasında Tekrarlayan Olumsuz Öz-Derin Düşünce ile öz-düşünüm arasında pozitif $(r=.65)$ ilişki olduğu görülmüştür. Ölçeğin test-tekrar test korelasyon katsayısı .76 olarak bulunmuş; düzeltilmiş madde-toplam korelasyonlarının .35 ile .69 arasında sıralandığ1 görülmüştür. Bu sonuçlara dayanarak Tekrarlayan Olumsuz Öz-Derin Düşünce Ölçeğinin psikoloji, psikiyatri ve eğitim alanında kullanılabilecek, geçerli ve güvenilir bir ölçme aracı olduğu söylenebilir.
\end{abstract}

Anahtar Kelimeler: Tekrarlayan Olumsuz Öz-Derin Düşünce, geçerlik, güvenirlik, faktör analizi.

\section{The Turkish version of the Self Rumination Scale: The Study of Validity and Reliability}

\begin{abstract}
The aim of this research is to adapt the Self Rumination Scale (Elliot \& Coker, 2008) to Turkish and to examine its psychometric properties. The research was conducted on total $573(286 \neg+287)$ university students from two universities. The validity and reliability of scale was investigated by test re-test, Cronbach alpha, exploratory and confirmatory factor analysis and criterion related validity methods. Self-reflection Scale was used for the criterion related validity. Results confirmatory factor analyses demonstrated that 10 items yielded one factor as original form and that the one-dimensional model was well fit $(x 2=53,97, \mathrm{df}=31$, $\mathrm{p}=.006, \mathrm{RMSEA}=.051, \mathrm{CFI}=.99, \mathrm{GFI}=.96, \mathrm{IFI}=.99, \mathrm{NFI}=.97, \mathrm{SRMR}=.039$ ). Factor loadings ranged from .44 ile .78. Cronbach alpha internal consistency coefficient was found as .86. In the concurrent validity significant relationships $(\mathrm{r}=.65)$ were found between the Self-rumination Scale and Self-reflection Scale. Testretest reliability coefficient was .76 . Corrected item-total correlations ranged from .35 to .69 . Overall results demonstrated that Self-rumination Scale can be named as a valid and reliable instrument that could be used in the field of psychology, psychiatry and education.
\end{abstract}

Keywords: Self rumination, validity, reliability, factor analysis.

\footnotetext{
* Dumlupınar Üniversitesi Eğitim Fakültesi, Rehberlik ve Psikolojik Danışmanlık ABD., Kütahya, hakansaricam@gmail.com

** Sakarya Üniversitesi, Eğitim Fakültesi, Eğitimde Psikolojik Hizmetler ABD, aakin@sakarya.edu.tr
} 


\section{GİRIŞ}

Günümüzde birçok insan farkında olmadan bazen derin düşüncelere dalmaktadır. Hatta bazıları vardır ki kendilerini bu derin düşüncelerden alamayıp çokça vakit harcamaktadır. Derin düşünceler kimi zaman gelecekte alınacak doğru kararlar için kendini düzenleme sisteminin bir parçası olabileceği gibi kimi zaman da takıntı haline gelip kişiyi içten içe tüketen bir yapıya dönüşebilmektedir. Martin ve Tesser'e (1996) göre ruminasyon, tekrarlayıcı düşüncenin farklı biçimlerine işaret eden bir terimdir. Başka bir deyişle ruminasyon: Belirli bir konu etrafında dönen, düşünmeyi gerektirecek koşullar ve ortam olmadığında dahi bazı aralıklarla sürekli tekrarlayan bilinçli düşünce biçimi olarak tanımlanabilir (Sarıçam, 2014a).

Tekrarlayan olumsuz öz-derin düşünce ise kişinin kendi düşünce ve hislerini incelemesi olarak bilinen (Elliot \& Coker, 2008), bütünlüklü bir yorumlamayı içeren ve olumsuz unsurların tekrarlayıcı döngülerle yaşandığı bir düşünce biçimi olarak tarif edilebilir (McIlwain, Taylor, \& Geeves, 2009). Trapnell ve Campbell (1999) derin düşünmeyle ilişkili "Kara kara düşünmek (Brooding)"=tekrarlayan olumsuz derin düşünceler ve "Zihninde tartmak, düşünüp taşınmak (Pondering)"=tefekkür olarak isimlendirdiği iki faktör tespit etmişlerdir (Treynor, Gonzalez, \& NolenHoeksema, 2003). Bu kavramların bizim literatürümüzdeki karşılıkları: kara kara düşünmek= tekrarlayan olumsuz derin düşünceler olarak ve zihninde tartmak, düşünüp taşınmak =tefekkür olarak adlandırılmaktadır (Sarıçam, 2014a). Kara kara düşünmek, öz-düşünüm veya içe-bakışın olumsuz bir çeşidi olup, "neden ben" sorusu ile ilgilenir ve problemin çözülemeyen noktasına odaklanması yönüyle tekrarlayan olumsuz öz-derin düşünce ile benzeşmektedir. Tıbbi çalışmalarda kara kara düşünmek olarak adlandırılan ruminasyon formunun depresyon ile anlamlı oranda ilişkili olduğu saptanmıştır (Siegle, Moore, \& Thase, 2004; Treynor ve diğerleri, 2003). Tekrarlayan olumsuz öz-derin düşünce, olumsuz kişisel anıların daha sıklıkla hatırlanmasına, çaresizlik hissi oluşturarak olumsuz düşünce biçiminin devam etmesine, kişinin sorunlarına etkili çözümler üretmesini azaltmasına neden olarak depresyona yatkınlık oluşturmaktadır (Lyubomirsky, Caldwell, \& Nolen-Hoeksema, 1998; Lyubomirsky, Tucker, Caldwell \& diğerleri, 1999). Tekrarlayan olumsuz öz-derin düşünce kendilikle ilgili olumsuzluklara yoğunlaştığı için mutluluk açısından zararlı olabilmektedir; benliği ile ilgili olumlu görüşlerine gölge düşen bireyin sonuç olarak mutluğu ile ilgili algılamaları da kötü yöne değişmektedir (Sarıçam, 2014b).

Nolen-Hoeksema'nın depresif ruminasyon kavramı temelinde geliştirdiği Tepki Biçimleri Teorisini (TBT) takiben kavramla ilgili birçok teori, model ve ölçek geliştirilmiştir (Papageiorgio, \& Wells, 2004). Elliot ve Coker (2008) tarafından geliştirilen Tekrarlayan Olumsuz Öz-Derin Düşünce Ölçeği bu ölçeklerden biri olup; yetişkinler için kendini değerlendirmeye yönelik 6'l1 derecelendirmeye ("1" Hiç katılmıorum- "6" Tamamen katıliyorum) dayalı bir ölçektir. Ölçeğin 1. maddesi ters kodlanmaktadır. Ölçekten alınabilecek toplam puan 10 ile 60 arasında değişmektedir. Yükselen puanlar yüksek düzeyde tekrarlayan olumsuz öz-derin düşünceyi göstermektedir. 10 maddeden oluşan Tekrarlayan Olumsuz ÖzDerin Düşünce Ölçeğinin Cronbach alfa iç tutarlılık güvenirlik katsayısı .91 olarak bulunmuştur. Tekrarlayan olumsuz öz-derin düşünce kavramının hem psikopatolojik süreçlerle ilişkili olması (Papageiorgio \& Wells, 2003; Rush \& Thase, 1999) hem de kişinin kendisi, kaygıları (Kashdan \& Roberts, 2007), üzüntüleri, yaşantıları hakkında tekrarlayıcı ve 
daimi düşünceler olarak zihinsel bir süreç (Conway, Csank, Holm, \& Blake, 2000; Watkins, 2008) olmasından dolayı özellikle son 20 yıl içinde birçok araştırmacı için hem teorik hem de deneysel olarak ilgi odağı olmasıyla birlikte bu çalışma için tetikleyici olmuştur. Bu çalışmanın amacı, Tekrarlayan Olumsuz ÖzDerin Düşünce Ölçeğini Türkçeye uyarlamak ve ölçeğin geçerlik ve güvenirliğini incelemektir.

\section{YÖNTEM}

\section{1 Çalışma grubu}

$\mathrm{Bu}$ araştırma iki ayrı üniversitede öğrenim gören toplamda $573 \quad(286+287)$ üniversite öğrencisi üzerinde yürütülmüştür. Öğrencilerin $79^{\prime}$ u fen bilgisi öğretmenliği, 118'i okul öncesi öğretmenliği, 94'ü psikolojik danışmanlık ve rehberlik, 90'1 sinıf öğretmenliği, 81'i sosyal bilgiler öğretmenliği ve 111 'i din kültürü ve ahlak bilgisi öğretmenliği bölümlerinde öğrenim görmektedir. Yaşları 18 ile 35 yaş arasında değişen ve yaş ortalaması 23.4 olan öğrencilerin 281'i (\% 49) erkek ve 292'si (\% 51) kız öğrenciden oluşmaktadır.

\subsection{Kullanılan ölçme araçları}

Çalışmada veri toplamak amaciyla Tekrarlayan Olumsuz Öz-Derin Düşünce Ölçeğinin yanı sıra ölçüt (uyum) geçerliliği için Öz-Düşünüm Ölçeği kullanılmıştır. Ayrıca demografik bilgilere ulaşmak için Kişisel Bilgi Formu dağıtılmıştır.

Öz-düşünüm Ölçeği (Self-reflection Scale): Elliot ve Coker (2008) tarafından geliştirilen, Akın ve diğerleri (2012) tarafından Türkçe'ye uyarlanan Öz-düşünüm Ölçeği 12 madde ve tek boyuttan oluşmaktadır ve bireyin kendisi hakkında bilgi vermesi (self report) esasına dayalı olan 6'lı ("1" Hiç katılmıorum- "6" Tamamen katıliyorum) derecelendirmeye sahip bir ölçme aracıdır. Ölçekten elde edilebilecek en yüksek puan 72 , en düşük puan ise $12^{\prime}$ dir.
Ölçek toplam bir öz-düşünüm puanı vermektedir. Ölçeğin 5., 7. ve 9. maddeleri ters kodlanmaktadır. Öz-düşünüm Ölçeğinin yapı geçerliği için 287 üniversite öğrencisinden elde edilen verilere doğrulayıcı faktör analizi uygulanmış ve ölçeğin orijinal formda olduğu gibi tek boyutta iyi uyum verdiği bulunmuştur $\left(\chi^{2}=\right.$ 78.74, $\mathrm{sd}=50, \mathrm{p}=.006, \mathrm{RMSEA}=.044, \mathrm{NFI}=.90$, $\mathrm{CFI}=.97, \mathrm{IFI}=.97, \mathrm{GFI}=.96, \mathrm{SRMR}=.047)$. Ölçeğin faktör yükleri .32 ile .63 arasında sıralanmaktadır. Ölçeğin Cronbach alfa iç tutarlılık güvenirlik katsayısı .71 olarak bulunmuş ve düzeltilmiş madde toplam korelasyon katsayılarının .21 ile .45 arasında değiştiği görülmüştür.

\section{3 İşlem}

Tekrarlayan Olumsuz Öz-Derin Düşünce Ölçeğinin uyarlama çalışması için ölçeği geliştiren Elliot ve Coker ile e-posta yoluyla iletişim kurulmuş ve ölçeğin uyarlanabileceğine ilişkin gerekli izin alınmıştır. Ölçeğin Türkçeye çevrilme süreci belli aşamalardan oluşmaktadır. Öncelikle ölçek İngiliz Dili ve Edebiyatı ile İngilizce öğretmenliği bölümü mezunu 5 dil uzmanı tarafından Türkçeye çevrilmiş ve daha sonra bu Türkçe formlar tekrar İngilizceye çevrilerek İngilizce ve Türkçeyi bilen 23 kişiye uygulanmıştır. Dilsel eşdeğerlik çalışmasında iki form arasındaki tutarlılı̆g 1 tespit etmek için korelasyon katsayıları incelenmiştir. Yine aynı dil uzmanları elde ettikleri Türkçe formlar üzerinde tartışarak anlam ve dilbilgisi açısından gerekli düzeltmeleri yapmış ve denemelik Türkçe form elde edilmiştir. Son aşamada bu form, psikolojik danışma ve rehberlik ve ölçme ve değerlendirme alanındaki birer öğretim üyesine inceletilerek görüşleri doğrultusunda Türkçe form üzerine bazı değişiklikler yapılmıştır. Hazırlanan Türkçe form çoğaltılarak üniversite öğrencilerine gerekli açıklama yapıldıktan sonra uygulanmış ve 
formlar toplanarak, verilerin bilgisayar ortamına aktarılması sağlanmıştır. Tekrarlayan Olumsuz Öz-Derin Düşünce Ölçeğinin yapı geçerliği için elde edilen verilere açıklayıcı faktör analizi (AFA) ve doğrulayıcı faktör analizi (DFA) yapılmıştır. AFA çok sayıda değişkenden (maddeden) bu değişkenlerin birlikte açıklayabildikleri az sayıda tanımlanabilen anlamlı yapılara ulaşmayı hedefler (Büyüköztürk, 2012). DFA ise kuramsal bir temele dayanarak çeşitli değişkenlerden oluşturulan faktörlerin gerçek verilerle ne derece uyum gösterdiğini değerlendirme amacıyla kullanılır. Yani DFA'da önceden belirlenmiş ya da kurgulanmış bir yapının toplanan verilerle ne derece doğrulandığı incelenmektedir (Sümer, 2000; Şimşek, 2007). Bu çalışmada AFA uygulanmasının nedeni Tekrarlayan Olumsuz Öz-Derin Düşünce Ölçeğinin orijinal formunun Türk üniversite öğrencileri üzerindeki yapısını açığa çıkarmak, DFA kullanılmasının nedeni orijinal formun faktör yapısının Türk bireyler üzerinde doğrulanıp doğrulanmadığını incelemektir (Büyüköztürk ve diğerleri, 2004). Uyum indekslerinde literatürde yaygin olarak kullanılan ve önerilen GFI, CFI, NFI, RFI ve IFI için > .90, RMSEA ve RMR için < .05 ölçüt olarak alınmıştır (Hu \& Bentler, 1999). Ortalama ve toplam puanlar arasındaki ilişkileri tespit etmek için Pearson Momentler Korelasyon Analizi uygulanmıştır. Tekrarlayan Olumsuz Öz-Derin Düşünce Ölçeğinin geçerlik ve güvenirlik analizleri için SPSS 17 ve LISREL 8.54 (Jöreskog \& Sörbom, 1996) programları kullanılmıştır.

\section{BULGULAR}

\subsection{Dilsel Eşdeğerlik}

İngilizce form puanları ile Türkçe form puanlar arasındaki korelasyon katsayısı .90 ve iki hafta arayla yapılan uygulamada Türkçe ve İngilizce formlar arasındaki korelasyon katsayısı 95 olarak bulunmuştur.

Tablo 1. Orijinal form ile Türkçe form arasındaki ilişkiye yönelik Pearson Momentler Çarpımı Korelasyon Analizi sonuçları

\begin{tabular}{cllll}
\hline & $\mathbf{N}$ & $\mathbf{X}$ & Standart sapma & $\mathbf{r}$ \\
\hline Türkçe form & 23 & 34.27 & 12.76 & $.90^{* *}$ \\
İngilizce form & 23 & 30.06 & 11.16 & \\
İlk uygulama & 23 & 34.27 & 12.76 & $.95^{* *}$ \\
İkinci uygulama & 23 & 33.32 & 12.30 & \\
\hline
\end{tabular}
${ }^{* *} \mathrm{p}<.01$

\subsection{Yapı Geçerliği}

Ölçeğin yapı geçerliliği için öncelikle bir üniversitenin çeşitli bölümlerinde öğrenim gören 286 öğrenciden elde edilen verilerin, faktör analizine uygunluğunu tespit etmek amaciyla Kaiser-Meyer-Olkin (KMO) katsayısı hesaplanmış ve Barlett Spehericity testi yapılmıştır. Verilerin faktör analizine uygunluğu için KMO .60 'dan yüksek ve Barlett testinin $\mathrm{p}<.01$ önem düzeyinde anlamlı çıkması gerekmektedir (Büyüköztürk ve diğerleri, 2004). Yapılan ana- liz sonucu KMO örneklem uygunluk katsayısı .82, Barlett testi $\chi 2$ değeri $665,102(\mathrm{p}<.001$, sd= 36) olarak bulunmuştur. Ölçeğin üniversite öğrencilerinden oluşan çalışma grubunda faktör yapısını ortaya koymak üzere açıklayıcı faktör analizi (AFA) yapılmıştır. Yapılan ilk uygulamada öz değeri 1'in üzerinde iki faktör tespit edilmiştir. Fakat birkaç maddenin iki faktör altında birbirine yakın yükler göstermesinden dolayı AFA yapılırken temel bileşenler tekniği ile eğik döndürme faktör çözümlemesi sonuçları tek faktörle sınırlandırılmış; böylece 
ölçeğin orjinali ile uyumlu tek faktörlü bir yapı elde etmek amaçlanmıştır. Analiz sonucunda faktör yüklerinin .44 ile .78 arasında değişmek- te olduğu görülmüş̧; toplam varyansin $\% 45$ 'ini açıklayan tek faktörlü bir yapı elde edilmiştir. Sonuçlar Tablo 2'de verilmiştir.

Tablo 2. AFA Faktör Yük ve Varyans Değerleri

\begin{tabular}{ll}
\hline Madde & Faktör yükleri \\
$\mathbf{1}$ & .44 \\
$\mathbf{2}$ & .64 \\
$\mathbf{3}$ & .60 \\
$\mathbf{4}$ & .73 \\
$\mathbf{5}$ & .75 \\
$\mathbf{6}$ & .70 \\
$\mathbf{7}$ & .58 \\
$\mathbf{8}$ & .77 \\
$\mathbf{9}$ & .78 \\
$\mathbf{1 0}$ & .71 \\
Varyans & $\% 45$ \\
\hline
\end{tabular}

Doğrulayıcı faktör analizi (DFA): Tekrarlayan Olumsuz Öz-Derin Düşünce Ölçeğinin yapı geçerliği için bir üniversitenin eğitim fakültesinde öğrenim gören 287 öğrenciden elde edilen verilere uygulanan doğrulayıcı faktör analizinde tek boyutlu modelin uyum indeksi değerleri: $\mathrm{x} 2=53,97, \mathrm{sd}=31, \mathrm{p}=.006$, RMSEA $=.051, \mathrm{CFI}=.99, \mathrm{GFI}=.96, \mathrm{IFI}=.99, \mathrm{NFI}=$ $.97, \mathrm{SRMR}=.039$ olarak bulunmuştur. Ölçeğe ait path diyagramı Şekil 1'de verilmiştir.
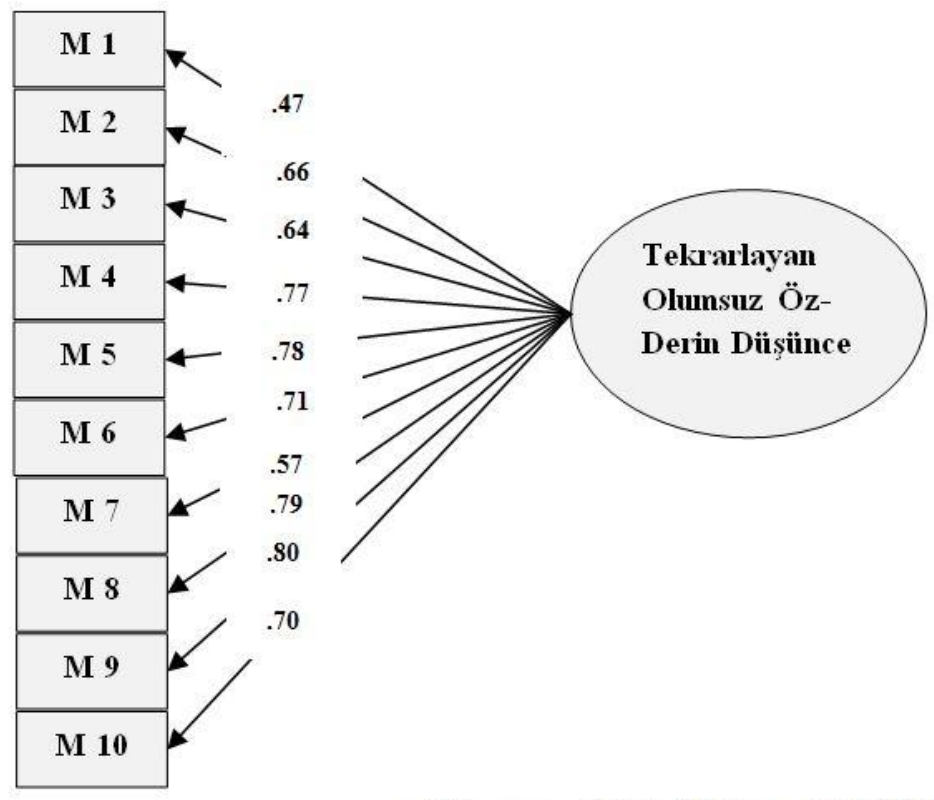

Chi-square $=53,97 \mathrm{df}=31, \mathrm{p}=0.06, \mathrm{RMSEA}=0,051$

Şekil 1. Tekrarlayan Olumsuz Öz-Derin Düşünce Ölçeği 'ne İlişkin Path Diagramı 
Ölçeğin ölçüt geçerliği çalışmasında tekrarlayan olumsuz öz-derin düşünce ile öz-düşünüm arasında pozitif ( $r=$.65) ilişki olduğu görülmüştür.

\subsection{Güvenirlik}

Tekrarlayan Olumsuz Öz-derin Düşünce Ölçeğinin Cronbach alfa iç tutarlık güvenirlik katsayıs1 .86 olarak bulunmuştur. Ayrıca ölçeğin test-tekrar test güvenirliği için ölçek 21 gün ara ile aynı çalışma grubundan 71 kişiye tekrar uygulandığında, iki uygulama arasındaki korelasyon katsayısı .76 olarak bulunmuştur.

\subsection{Madde analizi}

Yapılan analiz sonucunda ölçeğin düzeltilmiş madde-toplam korelasyonları .35 ile .69 arasında sıralanmaktadır. Bulgular Tablo 3'te gösterilmiştir.

Tablo 3. Düzeltilmiş madde toplam korelasyon değerleri

\begin{tabular}{|c|c|}
\hline Maddeler & $\begin{array}{c}\text { Düzeltilmiş madde top- } \\
\text { lam korelasyonları }\end{array}$ \\
\hline 1 & .35 \\
\hline 2 & .55 \\
\hline 3 & .46 \\
\hline 4 & .64 \\
\hline 5 & .66 \\
\hline 6 & .60 \\
\hline 7 & .47 \\
\hline 8 & .68 \\
\hline 9 & .69 \\
\hline 10 & .60 \\
\hline
\end{tabular}

Ayrıca toplam puanlara göre belirlenmiş $\% 27$ 'lik alt ve üst grupların madde puanlarındaki farklara ilişkin $t(\mathrm{sd}=497)$ değerlerinin ise $6.64(\mathrm{p}<.001)$ ile $18.48(\mathrm{p}<.001)$ arasında değiş̧tiği görülmüştür.

\section{TARTIŞMA VE ÖNERILER}

Bu çalışmada Tekrarlayan Olumsuz Öz-Derin Düşünce Ölçeğinin Türkçeye uyarlanması amaçlanmıştır. Bu amaç doğrultusunda ölçeğin geçerliği, faktör analizi ve benzer ölçek geçerliği ile belirlenmiştir. Ölçeğin Türkçe versiyonun uyum indeksi değerleri incelendiğinde, $\mathrm{x}^{2} / \mathrm{sd}=1.74$ değerinin 2 'nin altında olması uyum iyiliği değerinin mükemmel olduğunun göstergesidir (Erkuş, 2012; Şimşek, 2007). Benzer ölçek geçerliği çalışmasında kullanılan benzer ölçek ile uyarlanan ölçek arasındaki korelasyon katsayısı ne kadar büyükse ölçüt bağıntılı geçerlik o kadar iyi demektir (Ercan \& Kan, 2004). $\mathrm{Bu}$ iki geçerlik çalışmasından elde dilen sonuç- lar, araştırma literatüründe önerilen ve kabul edilebilir aralıklar arasında bulunmaktadır (Ercan \& Kan, 2004; Erkuş, 2012). Tekrarlayan Olumsuz Öz-Derin Düşünce Ölçeğinin güvenirlik çalışmaları sonuçlarına bakıldığında ise Cronbach-alfa iç tutarlık güvenirlik katsayısının alanyazında kabul edilen .70'ten (Baykul, 2000; Ercan \& Kan, 2004; Erkuş, 2012) yüksek olduğu ve test-tekrar test yöntemiyle elde edilen korelasyon katsayılarının literatürde kabul edilen genel ölçütlere uygun olduğu tespit edilmiştir. Ayrıca yapılan madde analizinde ölçekte yer alan 10 maddenin alt grupla üst grubu birbirinden anlamlı düzeyde ayırt ettiği görülmüş ve madde toplam korelasyonu katsayılarının ise literatürde kabul edilen değer olan $.30^{\prime}$ dan büyük olduğu tespit edilmiştir.

Ölçeğin bireylerin tekrarlayan olumsuz özderin düşünce düzeyleri ile ilgili bilgi vermesi, depresyonun tetikleyicileri hakkında bilgi 
sağlamasının yanı sıra yapılacak psikolojik danışma ve sağaltım uygulamalarına da birçok kolaylık oluşturacağı düşünülmektedir. Ölçeğin uyarlanmasında AFA temel bileşenler tekniği ile eğik döndürme yapılmadan, maddelerin kültürümüzde farklı boyutlarda toplanıp toplanamayacağı incelenebilir. $\mathrm{Bu}$ çalışma üniversite öğrencilerinden elde edilen verilerle yürütülmüştür, fakat ölçeğin psikometrik özelliklerinin farklı çalışma gruplarıyla incelenmesi son derece önemlidir. Ayrıca, ölçeğin ruminasyon, anksiyete, depresyon, stress düzeylerini belirleyen geçerli ve güvenilir ölçme araçlarıyla ilişkisine bakılabilir. 


\section{Kaynakça}

Akın, A., Satici, S. A., Kayıs, A. R., Çitemel, N., \& Usta, F. (2012, July). A Turkish Version of Self-Reflection Scale. Paper presented at the 33rd International Conference of the Stress and Anxiety Research Society (STAR), July, 2-4, Palma de Mallorca, Spain.

Baykul, Y. (2000). Eğitimde ve psikolojide ölçme: Klasik test teorisi ve uygulaması. Ankara: ÖSYM Yayınları. Büyüköztürk, Ş., Akgün, Ö., Kahveci, Ö., \& Demirel, F. (2004). Güdülenme ve Öğrenme Stratejileri Ölçeği'nin Türkçe formunun geçerlik ve güvenirlik çalışması. Kuram ve Uygulamada Ĕ̆itim Bilimleri, 4(2), 207-239.

Conway, M., Csank, P. A. R., Holm, S. L., \& Blake, C. K. (2000). On assessing individual differences in rumination on sadness. Journal of Personality Assessment, 75, 404-425.

Elliot, I., \& Coker, S. (2008). Independent self-construal, self-reflection, and self-rumination: A path model for predicting happiness. Australian Journal of Psychology, 60(3), 127-134.

Ercan, İ., \& Kan, İ. (2004). Ölçeklerde güvenirlik ve geçerlik. Uludă̆ Üniversitesi Tıp Fakültesi Dergisi, 30(3), 211-216.

Erkuş, A. (2012). Psikolojide ölçme ve ölçek geliştirme-I. Ankara: PegemA Yayıncılık.

Hu, L. T., \& Bnetler, P. M. (1999). Cutoff criteria for fit indexes in covariance structural analysis: Conventional criteria versus new alternatives. Structural Equation Modeling, 6, 1-55.

Jöreskog, K., \& Sörbom, D. (1996). LISREL 8: User's Reference Guide. Chicago, IL: Scientific Software International Inc.

Kashdan, T. B., \& Roberts, J. E. (2007). Social anxiety, depressive symptoms, and post-event rumination: Affective consequences and social contextual influences. Journal of Anxiety Disorders, 21, 284-301.

Lyubomirsky, S., Tucker, K. L., Caldwell, N.D., \& diğerleri. (1999). Why ruminators are poor problem solvers: Clues from the phenomenology of dysphoric rumination. Journal of Personality and Social Psychology, 77, 1041-1060.

Lyubomirsky, S., Caldwell, N. D., \& Nolen-Hoeksema, S. (1998). Effects of ruminative and distracting responses to depressed mood on retrieval of autobiographical memories. Journal of Personality and Social Psychology, 75, 166-177.

Martin, L. L., \& Tesser, A. (1996). Some ruminative thoughts. In: R. S. Wyer (ed.), Advances in social cognition. (pp.1-47). Mahwah, NJ: Lawrence Erlbaum.

McIlwain, D., Taylor, A., \& Geeves, A. (2009). Fullness of Feeling: Reflection, rumination, depression and the specificity of autobiographical memories. In Christensen W, Schier E, and Sutton J. (Eds.), ASCS09: Proceedings of the 9th Conference of the Australasian Society for Cognitive Science [serial on the internet] 2012 [cited 2012-04-11], 238-244. Available from:http://www.maccs.mq.edu.au/news/conferences/2009/ASCS2009/html/mcilwain.html

Papageiorgio, C., \& Wells, A. (2003). An empirical test of a clinical metacognitive model of rumination and depression. Cognitive Therapy and Research, 27, 261-273.

Papageiorgio, C., \& Wells, A. (2004). Nature, functions and beliefs about depressive rumination: In Papageiorgio, C, Wells A (editors). Depressive rumination nature, theory and treatment. West Sussex: John Wiley and sons Ltd.

Rush, A. J., \& Thase, M. E. (1999). Psychotherapies for depressive disorders: A review: In M. Maj, N. Sartorius (Eds.), Depressive disorders (WPA Series in Evidence and Experience in Psychiatry). New York: Wiley.

Sarıçam, H. (2014a). Çözüm odaklı kısa süreli yaklaşıma dayalı bir müdahale programının ruminasyon üzerinde etkisi. (Doktora tezi). Sakarya Üniversitesi, Sakarya.

Sarıçam, H. (2014b). Öz-derin düşünce. İçinde Akın, A., \& Akın, Ü. (Eds), Çözüm odaklı kısa süreli grupla psikolojik danışma uygulamaları. Ankara, Nobel Akademi Yayınları.

Satici, S. A., \& Akın, A. (2012). A Turkish adaptation study of Self-Rumination Scale. Paper presented at the 33rd International Conference of the Stress and Anxiety Research Society (STAR), 2-4 July, Palma de Mallorca, Spain. 
Siegle, G. J., Moore, P. M., \& Thase, M. E. (2004). Rumination: One construct, many features in healthy individuals, depressed individuals, and individuals with lupus. Cognitive Therapy and Research, 28(5), 645-668.

Sümer, N. (2000). Yapısal eşitlik modelleri: Temel kavramlar ve örnek uygulamalar. Türk Psikoloji Yazıla$r, 3(6), 49-74$

Şimşek, Ö. F. (2007). Yapısal eşitlik modellemesine giriş: Temel ilkeler ve Lisrel uygulamaları. Ekinoks Yayınlar1, Ankara.

Trapnell, P. D., \& Campbell, J. D. (1999). Private self-consciousness and the five-factor model of personality: Distinguishing rumination from reflection. Journal of Personality and Social Psychology, 76, 284304.

Treynor, W., Gonzalez, R., \& Nolen-Hoeksema, S. (2003). Rumination reconsidered: A psychometric analysis. Cognitive Therapy and Research, 27, 247-259.

Watkins, R. (2008). Constructive and unconstructive repetitive thought. Psychological Bulletin, 134(2), 163-206. 


\section{Extended Summary}

\section{Introduction}

According to Martin and Tesser (1996), rumination is a well-known term that refers to several varieties of repeated thinking. That is, rumination refers to the entire class of thought that has an inclination to repeat. Rumination, crudely defined as persistent, recyclic, depressive thinking, is a relatively common response to negative moods and a salient cognitive feature of dysphoria and major depressive disorder. According to Nolen-Hoeksema (1991), self-rumination involves "recurrently focusing on the fact that one is depressed; on one's symptoms of depression; and on the occasions, meanings, and consequences of depressive symptoms". Examples of self-ruminative thoughts include: "why am I such a loser?", "my mood is so bad," "why do I react so negatively?", "I just can't cope with anything," and "why don't I feel like doing anything?". Namely, rumination "consists of repetitive thoughts concerning one's present distress and the circumstances surrounding the sadness" (Conway, Csank, Holm, \& Blake, 2000)

Original form of Self-rumination Scale that was developed by Elliot and Coker, it is a self-report measure of self-rumination levels. Scoring of the measure is based on a 6-point degrees type scale regarding the frequency with which the behavior of interest is exhibited where $1=$ strongly disagree, $6=$ strongly disagree. Higher scores, therefore, indicate greater self-rumination (range=1-60). Results of exploratory factor analysis indicated that the model consists of one factors and 10 items. The Cronbach alpha internal consistency coefficient of the scale was .91 .

In view of the potential to advance our knowledge of the mechanisms of depressive onset, maintenance, and recurrence, rumination has attracted increasing theoretical and empirical interest in the past 20 years. The aim of this research is to adapt the Self Rumination Scale (Elliot \& Coker, 2008) to Turkish and to examine its psychometric properties.

\section{Method}

\section{Participants}

Participants were total 573 university students (292 (51\%) were female, 281 (49\%) were male) who were enrolled in two mid-state university. (287+286 students), in Turkey. Their ages ranged from 18 to 35 years and the mean age of the participants was 23.4 years.

\section{Instrument}

Self-reflection Scale (PVS): Self-reflection Scale was developed by Elliot and Coker (2008). Turkish adaptation of this scale was done by Satici and Akin (2012). This scale is a 12-items self-report measurement and consists of one factor. The results of confirmatory factor analysis indicated that the model was well fit and Chi-Square value $\left(x^{2}=78.74, \mathrm{df}=50, \mathrm{p}=.006\right)$ which was calculated for the adaptation of the model was found to be significant. The goodness of fit index values of the model were RMSEA $=.044, \mathrm{NFI}=.90$, $\mathrm{CFI}=.97, \mathrm{IFI}=.97, \mathrm{GFI}=.96, \mathrm{SRMR}=.047$. Factor loadings ranged from .32 to .63 . The Cronbach alpha coefficient of the questionnaire was .71 and the corrected item-total correlations of SRS ranged from .21 to .45 . 


\section{Procedure}

Primarily the Self-rumination Scale was translated into Turkish by five academicians from English Language and Literature department. Before validity and reliability studies, to examine the language equivalency of the scale the correlations between Turkish and English forms were calculated. In this study exploratory factor analysis (EFA) was performed to examine the factor structure of the scale according to the data obtained from the Turkish students and confirmatory factor analysis (CFA) was executed to confirm the original scale's structure in Turkish culture. For reliability analysis test-retest and internal consistency coefficients were calculated and for the validity analysis, the item-total correlations, and the differences between mean scores of upper $27 \%$ and lover $27 \%$ groups were examined. For the analysis of data, computer programs SPSS 17 and LISREL 8.54 were utilized.

\section{Results}

There is a significant correlation between the original and Turkish version of the scale in the equivalency was .90 level $(\mathrm{p}=.00)$. Kaiser-Meyer-Olkin (KMO) measure of sampling adequacy of .82 and a significant result on Bartlett's test of Sphericity $\chi 2=665,102(\mathrm{p}<.001, \mathrm{df}=36)$. Results confirmatory factor analyses demonstrated that 10 items yielded on one factor as original form and that the one-dimensional model was well fit $(x 2=53,97, \mathrm{df}=31, \mathrm{p}=.006, \mathrm{RMSEA}=.051, \mathrm{CFI}=.99, \mathrm{IFI}=.99, \mathrm{NFI}=.97, \mathrm{RFI}=.96, \mathrm{GFI}=.96$, $\mathrm{SRMR}=.039$ ). Factor loadings ranged from .44 to .78 . Cronbach alpha internal consistency coefficient was found as .86 . In the concurrent validity a positive relationship $(r=.65)$ was found between the Selfrumination Scale and Self-reflection Scale. Test-retest reliability coefficient was .76. Corrected item-total correlations ranged from .35 to .69 .

\section{Discussion}

As a result, it is possible to say that the Self-rumination Scale is a valid and reliable measurement tool to be used for the purpose of measuring self-rumination levels of individuals. The scale can be used in researches into personality and in the process of psychological counseling. The present research was carried out on the basis of data from university students. It would be possible analyze the psychometric characteristics and the factor structure of the scale using in different samples in further studies. Morover, it can be used as an efficient instruments in order to assess rumination, anxiety, depression, and stress levels. 